\title{
Direct evidence for the participation of gap junction- mediated intercellular communication in the transmission of damage signals from $\alpha$-particle irradiated to nonirradiated cells
}

\author{
Edouard I. Azzam*, Sonia M. de Toledo*, and John B. Little ${ }^{\dagger}$ \\ Department of Cancer Cell Biology, Laboratory of Radiobiology, Harvard School of Public Health, Boston, MA 02115 \\ Edited by Richard B. Setlow, Brookhaven National Laboratory, Upton, NY, and approved October 27, 2000 (received for review August 30, 2000)
}

It has generally been considered that important biological effects of ionizing radiation arise as a direct consequence of DNA damage occurring in irradiated cells. We have examined this hypothesis by exposing cells to very low fluences of $\alpha$-particles, similar to those emitted by radon gas, such that as few as $1 \%$ of the cells in a population are traversed by a particle and thus receive any radiation exposure. By using the endpoints of changes in gene expression and induction of DNA damage, we show that nonirradiated "bystander" cells participate in the overall response of confluent density-inhibited populations of cultured fibroblast and epithelial cells. By in situ immunofluorescence techniques and the use of cells genetically compromised in their ability to perform gap junction intercellular communication, we present direct evidence for the involvement of connexin43-mediated intercellular communication in the transmission of damage signals to nonirradiated cells. Induction of the stress-inducible $\mathrm{p} 21^{\text {Waf1 }}$ protein in aggregates of neighboring cells far exceeding the fraction of cells whose nucleus has been traversed occurred in gap junction-competent cells only. These changes in p21Waf1 expression correlated with both the induction of DNA damage (as measured by micronucleus formation) as well as increased Ser-15 phosphorylation of p53.

thas long been thought that the important biological effects of radiation in a cell population are a direct consequence of DNA damage occurring in the irradiated cells: unrepaired or misrepaired DNA damage in these cells is responsible for the genetic effects of radiation. Presumably, no effect would be expected in cells in the population that received no direct radiation exposure. Recently, however, evidence has been presented indicating that genetic changes such as increased levels of sister chromatid exchanges $(1,2)$, mutations $(3,4)$, micronuclei $(5)$, and DNA damage-inducible proteins $(6,7)$ occur in a greater-thanexpected number of cells in cultures exposed to very low fluences of $\alpha$-particles, fluences in which only a small fraction of the cells are actually traversed by a particle track and thus directly exposed to radiation. Finally, it has been shown that when some cells were labeled with tritiated thymidine in a three-dimensional multicellular cluster model, a cytotoxic effect was transmitted to adjoining nonlabeled cells present in the same cluster (8).

Overall, these studies indicate that radiation traversal through the nucleus of a cell is not a necessary prerequisite to producing genetic damage or a biological response; cells in a population that are in the vicinity of directly hit cells can also respond to the radiation exposure. These nonirradiated cells that express genetic damage or changes in the expression of stress-induced genes have been termed "bystander cells." The present investigation was designed to determine the mechanisms by which damage signals may be transmitted from irradiated to nonirradiated bystander cells.
We previously presented preliminary evidence for the involvement of gap junction-mediated intercellular communication (GJIC) in the molecular events leading to the modulation of gene expression in bystander cells (7). In these studies, confluent density-inhibited cultures of normal human fibroblasts were exposed to low fluences of $\alpha$-particles in the presence or absence of lindane, a chemical inhibitor of GJIC. Changes in gene expression were measured by Western blotting. The participation of bystander cells in the overall cellular response to the radiation stress was inferred from the observations that, the effect was significantly greater than expected based on the fraction of directly irradiated cells in the population, and that it was reduced in the presence of lindane.

In the present study, we further explored the involvement of GJIC in the response of bystander cells in confluent cultures exposed to fluences of $\alpha$-particles where a very small fraction of cells' nuclei were traversed by a particle track. By using the endpoints of p53 and p21 Waf1 expression and induction of DNA damage, we present direct evidence for the involvement of connexin43-mediated intercellular communication, by in situ immunofluorescence techniques and by the use of cells genetically compromised in their ability to perform GJIC.

\section{Materials and Methods}

Cell Culture. Human cells. AG1522 normal human-diploid skin fibroblasts were obtained from the Coriell Cell Repositories, Camden, NJ. HLF1 normal human-diploid lung fibroblasts were obtained from the American Type Culture Collection. Cells destined for $\alpha$-particle irradiation were grown in 36-mm stainless steel dishes with $1.5-\mu$ m-thick replaceable mylar bottoms (9) at a seeding density of about $1.2 \times 10^{5}$ cells per dish. The mylar surface was precoated with fibronectin to facilitate cell attachment. The cells were subsequently fed on days 5, 7, and 9 with Eagle's MEM supplemented with $15 \%$ (vol/vol) heatinactivated FCS, penicillin 50 units $/ \mathrm{ml}$, and streptomycin 50 $\mu \mathrm{g} / \mathrm{ml}$. Experiments were started $48 \mathrm{~h}$ after the last feeding. At that time, $95-98 \%$ of the cells were in $\mathrm{G}_{0} / \mathrm{G}_{1}$ as determined by

\footnotetext{
This paper was submitted directly (Track II) to the PNAS office.
}

Abbreviations: GJIC, gap junction-mediated intercellular communication; MEF, mouse embryo fibroblast; $\mathrm{PBS}^{+}$, PBS supplemented with $1 \mathrm{mM} \mathrm{MgCl}$ and $0.1 \mathrm{mM} \mathrm{CaCl}_{2}$.

*Present address: Department of Radiology, New Jersey Medical School, Newark, NJ 07103.

†To whom reprint requests should be addressed at: Department of Cancer Cell Biology, Laboratory of Radiobiology, Harvard School of Public Health, 665 Huntington Avenue, Boston, MA 02115. E-mail: jlittle@hsph.harvard.edu.

The publication costs of this article were defrayed in part by page charge payment. This article must therefore be hereby marked "advertisement" in accordance with 18 U.S.C. $\S 1734$ solely to indicate this fact.

Article published online before print: Proc. Natl. Acad. Sci. USA, 10.1073/pnas.011417098. Article and publication date are at www.pnas.org/cgi/doi/10.1073/pnas.011417098 
labeling with ${ }^{3} \mathrm{H}$ thymidine and/or flow cytometry. To eliminate complications in the interpretations of results due to changes in cellular sensitivity to radiation at different phases of the cell cycle, the cells were synchronized in $\mathrm{G}_{0} / \mathrm{G}_{1}$ by confluent densityinhibition of growth. Importantly, this protocol maximizes interaction among the cells. Cells in passages 10-11 maintained in a $37^{\circ} \mathrm{C}$ humidified incubator (atmosphere $=5 \% \mathrm{CO}_{2}$ in air) were used in the experiments. Control cells were sham-irradiated and handled in parallel with the test cells.

Mouse embryo fibroblasts (MEFs). Wild-type and connexin43-l- primary MEFs were established in our laboratory with day 9 embryos from a pregnant female mouse heterozygous for gap junction membrane-channel protein $\alpha-1$ (commonly known as connexin43) that was mated to a male of the same genotype. The mice were a generous gift from Caterina Sellito, Harvard Medical School (Boston), who originally purchased them from The Jackson Laboratory. Genetic typing of the established cells was carried out according to a 3-primer protocol from The Jackson Laboratory. The phenotype was further confirmed by transfer of Lucifer yellow dye between cells in a confluent culture by the scrape-loading technique (10). Cells in passages 6-9 were used for the experiments. The cells were grown in modified Eagle's medium with Earle's balanced salt solution supplemented with 50\% more vitamins and essential amino acids (except glutamine), 100\% more nonessential amino acids, and $1 \mathrm{mM}$ sodium pyruvate (D medium, GIBCO). The medium was supplemented with $15 \%$ (vol/vol) heat-inactivated FCS. For the experiments, cells were seeded at a density of about $0.5 \times 10^{6}$ cells per $36-\mathrm{mm}$ stainless steel dish with replaceable mylar bottom. The cells were fed twice at 48-h intervals after seeding, and experiments were started $48 \mathrm{~h}$ after the last feeding. At this stage, the cells were confluent and were sensitive to contact inhibition of growth. Furthermore, control cells from either strain did not loose contact inhibition or express morphologically transformed foci (11) in monolayer cultures (maintained in the confluent state for 7 weeks and fed every 5 days with fresh medium).

Rat liver epithelial cells. WB-F344 and WM-aB1 cell lines (both GJIC-competent and GJIC-deficient) were a generous gift from James Trosko (Michigan State University, East Lansing). The WM-aB1 cells were derived from a mutant clone of WB-F344 cells (12). The cells were cultured according to the protocol described for MEFs and exposed to $\alpha$-particles in the confluent density-inhibited state. Both cell strains were very sensitive to contact inhibition of growth in a manner similar to the human fibroblasts and MEFs described above, and hence complications in the interpretation of microdosimetric measurements for $\alpha$-type experiments are eliminated.

Irradiation. For $\alpha$-particle irradiation, cells were exposed to a ${ }^{238} \mathrm{Pu}$ collimated source at a dose rate of $9.9 \mathrm{cGy} / \mathrm{min}$, as described (9). The source was located inside of a helium-filled Plexiglas box. Irradiation was carried out from below, through the mylar base, with $\alpha$-particles at an average energy of 3.65 million electronvolts at the cell layer. The source was fitted with a photographic shutter to allow accurate delivery of the specific radiation dose. Microscopic examination of pits etched in CR-39 plastic after a 1-min exposure showed no source hot spots or cold spots down to the $2,500 \mu \mathrm{m}^{2}$ level. The fraction of cells whose nucleus was actually traversed by an $\alpha$-particle was derived by using Poisson statistics and estimates involving cell geometry, $\alpha$-particle fluence, and energy loss.

Western Analysis. After irradiation, confluent density-inhibited cultures were held at $37^{\circ} \mathrm{C}$ in $5 \% \mathrm{CO}_{2}$ atmosphere for various time intervals before harvesting for analysis. The cells were pelleted, rinsed in PBS, repelleted, and lysed in chilled RIPA buffer (50 mM Tris $\cdot \mathrm{Cl}$, pH 7.5/150 mM NaCl/1\% Nonidet
P-40/0.5\% sodium deoxycholate/0.1\% SDS). The RIPA buffer was supplemented with the following protease and phosphatase inhibitors: PMSF $(1 \mathrm{mM})$, aprotinin $(1 \mu \mathrm{g} / \mathrm{ml})$, pepstatin $(1$ $\mu \mathrm{g} / \mathrm{ml})$, leupeptin $(1 \mu \mathrm{g} / \mathrm{ml})$, sodium fluoride $(50 \mathrm{mM})$, and sodium orthovanadate $(1 \mathrm{mM})$. Anti-p21 ${ }^{\text {Waf1 }}(\mathrm{Ab}-1)$ and antip53 (Ab-6) against-human proteins, anti-p53 (Ab-7) and antip21 Waf1 (Ab-6) against-mouse and -rat proteins, and anti- $\alpha$ tubulin (Ab-1, used to verify equal loading of the samples) were obtained from Oncogene Science. An anti-mouse Ig-G secondary antibody conjugated with horseradish peroxidase was used to detect the various proteins by chemiluminescence.

Immunofluorescence. Confluent cell cultures grown on mylar surfaces were rinsed in PBS supplemented with $1 \mathrm{mM} \mathrm{MgCl}_{2}$ and $0.1 \mathrm{mM} \mathrm{CaCl}_{2}\left(\mathrm{PBS}^{+}\right)$, and were fixed in $3 \%$ (vol/vol) paraformaldehyde in $\mathrm{PBS}^{+}$. After a 5 -min rinse in $50 \mathrm{mM} \mathrm{NH}_{4} \mathrm{Cl}$ and $2 \mathrm{PBS}^{+}$rinses, the cells were permeabilized in ice-cold Triton-X buffer $\left(50 \mathrm{mM} \mathrm{NaCl} / 3 \mathrm{mM} \mathrm{MgCl}_{2} / 200 \mathrm{mM}\right.$ sucrose $/ 10 \mathrm{mM}$ Hepes, $\mathrm{pH} 7.4 / 0.5 \%$ Triton $\mathrm{X}-100$ in water). The cell monolayers were subsequently blocked in $1 \% \mathrm{BSA}$ and reacted to the respective antibody-against-human or -rodent $\mathrm{p} 21^{\text {Waf1 }}$ according to the protocol of Eckner et al. (13). After incubation with an FITC-conjugated goat anti-mouse IgG secondary antibody (Sig$\mathrm{ma}$ ), the monolayers were washed at least five times with $\mathrm{PBS}^{+}$. Antifade (Oncor) was used in mounting the samples. Microscopy of coded samples was carried out by using a Leica TCSNT scanning confocal microscope equipped with an argon laser (excitation at $488 \mathrm{~nm}$ ). Experiments were repeated at least three times.

GJIC. The scrape-loading and dye-transfer techniques of El-Fouly et al. (10) were used to measure GJIC. Briefly, confluent density-inhibited cells in 60-mm polystyrene dishes were rinsed with $\mathrm{PBS}^{+}$, and $0.05 \%$ Lucifer yellow in $\mathrm{PBS}^{+}$was added to the cells. The cell monolayer was scraped with a scalpel blade and kept in the dark for approximately 3-5 min. After incubation, the dye solution was decanted, and the monolayer was rinsed three times with $\mathrm{PBS}^{+}$and viewed with a Zeiss II UV-microscope.

Micronucleus Assay. The frequency of micronucleus formation was measured by using the cytokinesis-block technique developed by Fenech and Morley (14). Briefly, after experimental treatments, confluent cultures were dissociated by trypsinization. Approximately $3 \times 10^{4}$ cells were plated in $2 \mathrm{ml}$ of growth medium in chamber flaskettes (Nunc) in the presence of $2 \mu \mathrm{g} / \mathrm{ml}$ cytochalasin $\mathrm{B}$ and were incubated at $37^{\circ} \mathrm{C}$. After $72 \mathrm{~h}$, the cells were rinsed twice with $\mathrm{PBS}^{+}(\mathrm{pH} 7.4)$ and fixed in cold methanol. After air drying, the cells were stained with Hoechst 33342 solution $(1 \mu \mathrm{g} / \mathrm{ml})$ and viewed under a fluorescent microscope. At least 500 cells were examined, and micronuclei in binucleate cells only were considered for analysis.

\section{Results}

In Situ Detection of Bystander p21 Waf1 Induction in Confluent DensityInhibited Populations of Human-Diploid Fibroblasts Exposed to Very Low Mean Doses of $\alpha$-Particles: The Effect of GJIC Inhibitors. We have shown (7) that induction of the p53 signaling pathway can be detected by Western analyses in confluent human-diploid fibroblast cultures exposed to mean doses of $\alpha$-particles as low as 0.3 cGy. The protein analyses data in Fig. $1 A$ extend our previous studies and show that $\mathrm{p} 53$ and $\mathrm{p} 21^{\mathrm{W}}$ af 1 are also significantly induced in AG1522 skin and HLF-1 lung fibroblasts exposed to low mean doses. An increase of 2.0- to 2.5-fold in p21 Waf1 levels measured by densitometry occurred in AG1522 cells exposed to a mean dose as low as $0.16 \mathrm{cGy}$. These results confirm our previous findings with other human fibroblast strains (7) and show that induction of these proteins can be detected by Western analyses at yet lower mean doses. At a dose of 0.16 cGy to the 
A



B


Fig. 1. (A) Western blot analysis of $\mathrm{p} 53$ and $\mathrm{p} 21^{\text {Waf1 }}$ expression levels in low fluence $\alpha$-particle exposed normal human fibroblasts. Confluent densityinhibited AG1522 skin or HLF-1 lung fibroblasts were exposed to $\alpha$-particles doses ranging from 0.16 to $85 \mathrm{cGy}$ and held at $37^{\circ} \mathrm{C}$ for $3 \mathrm{~h}$. Cell lysates from irradiated and control nonexposed cultures were prepared and examined. (B) In situ immunofluorescence detection of p2 $1^{\text {Waf1 }}$ in control and $\alpha$-particle exposed (0.3 cGy) AG1522 density-inhibited cultures where induction is seen to occur in aggregates of cells. About 1 cell in 50 would be traversed by an $\alpha$-particle at this mean dose. overall culture, about $1 \%$ of the cells' nuclei would be traversed by an $\alpha$-particle. The results of an in situ immunofluorescence study for $\mathrm{p} 21^{\text {Waf1 }}$ expression carried out in parallel in AG1522 cultures exposed to $0.3 \mathrm{cGy}$ is shown in Fig. $1 B$. As can be seen, staining occurs in aggregates of cells. At this dose, about $2 \%$ of the nuclei would be irradiated. The magnitude of the response at low-mean doses (shown in Fig. $1 A$ ), coupled with the immunofluorescence studies that showed that whenever $\mathrm{p} 21^{\text {Waf1 }}$ was induced it occurred in aggregates of neighboring cells (Fig. 1B), strongly support the view that bystander cells participate in the overall response of the exposed confluent cultures.

We have shown by Western blot analyses that cellular exposure to lindane ( $\gamma$-isomer of hexa-chloro-cyclo-hexane), an inhibitor of gap junctions that mediates intercellular communication (15), prevented detectable induction of $\mathrm{p} 21^{\text {Waf1 }}$ in confluent cultures exposed to low fluences of $\alpha$-particles (7). As lindane may have effects other than inhibition of connexin43-mediated intercellular communication, we tested the generality of the response by using other gap junction inhibitors. The data in Fig. $2 A$ indicate that, similarly to lindane, the inhibitors DDT [1,1'bis(pchlorophenyl)-2,2,2-trichloroethane] and dieldrin also reduced $\mathrm{p} 21^{\mathrm{Waf} 1}$ induction by low fluence exposure (1 cGy), albeit to different extents. Importantly, the in situ immunofluorescence data in Fig. $2 B$ show clearly that exposure of confluent cultures to lindane beginning $2 \mathrm{~h}$ before irradiation (mean dose of $0.3 \mathrm{cGy}$ ) and continuing until paraformaldehyde fixation $3 \mathrm{~h}$ later, resulted in the inhibition of the aggregate pattern of p21 Waf1 induction (Fig. 2B Right) that typically occurs in control irradiated cultures (Fig. $2 B$ Center). In irradiated cultures treated
A

p21 Waf1

$\alpha$-tubulin
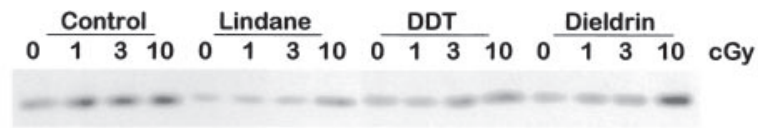

$-1-1-$

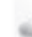

B
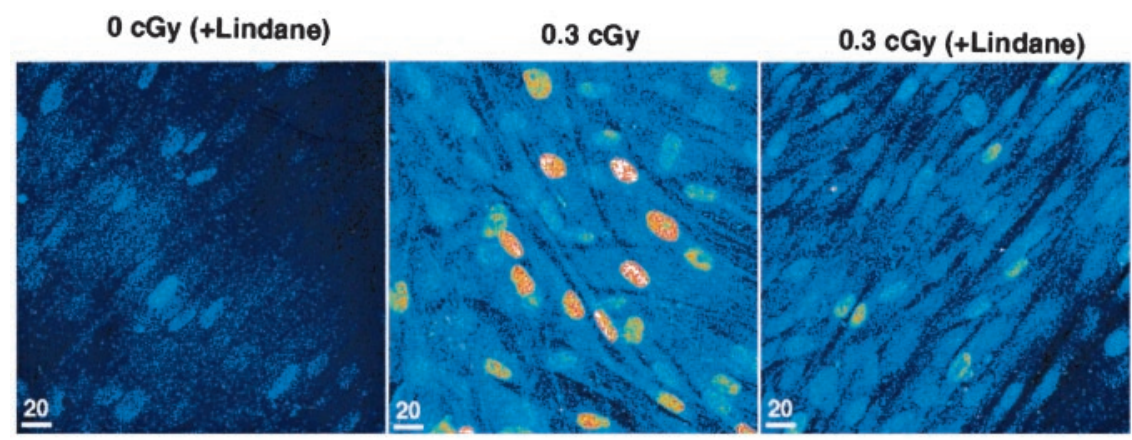

C

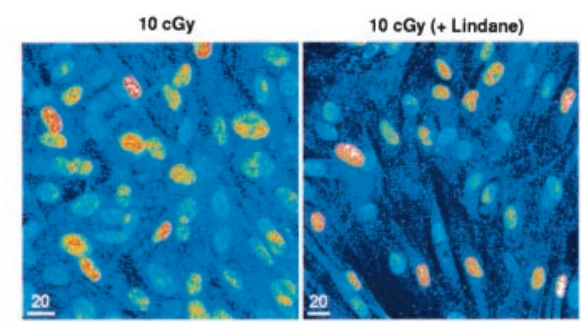

Fig. 2. (A) Western analysis of p21 Waf1 expression in $\alpha$-particle-irradiated AG1522 human fibroblasts in the presence or absence of lindane $(40 \mu \mathrm{M}), \mathrm{DDT}$, or dieldrin. At 10 cGy, by which about $50-60 \%$ of the cells' nuclei are traversed by an $\alpha$-particle track, p21 Waf1 is induced in the presence or absence of the inhibitors. At $1 \mathrm{cGy}$, by which only $7 \%$ of the cells in the culture would have their nuclei traversed by an $\alpha$-particle, p21 Waf1 induction is not detected in the presence of any of the inhibitors. (B). In situ immunofluorescence detection of p21Waf1 expression in nonirradiated lindane-treated $(40 \mu \mathrm{M})$, and irradiated AG1522 cultures exposed to 0.3 cGy $\alpha$-particles in the presence or absence of lindane. The absence of induced aggregates of cells in the irradiated and lindane-pretreated cultures indicates that GJIC contributes to the bystander response. (C) In situ immunofluorescence detection of p21Waf1 expression in AG1522 cultures exposed to 10 cGy in the presence or absence of lindane. 

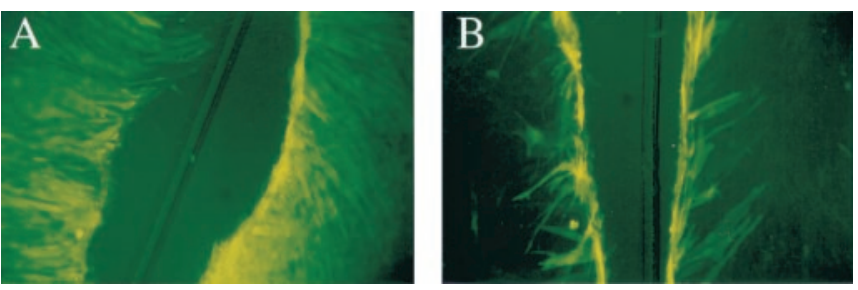

Fig. 3. (A) Transfer of the fluorescent dye Lucifer yellow through gap junction in AG1522 confluent density-inhibited cultures, and ( $B$ ) inhibition of its transfer to adjacent cells by $40 \mu \mathrm{M}$ lindane.

with lindane, $\mathrm{p} 21^{\text {Waf1 }}$ was induced primarily in single cells. These data further implicate GJIC in the bystander $\mathrm{p} 21^{\text {Waf1 }}$ response observed after exposure to fluences where a very small fraction of cell nuclei in the exposed culture is traversed by an irradiating $\alpha$-particle. At higher mean doses, where most of the cell nuclei in the exposed culture is traversed by a particle track, lindane did not have a clear attenuating effect on the $\mathrm{p} 21^{\text {Waf1 }}$ response. The data in Fig. $2 C$ indicate that when confluent AG1522 cultures are exposed to a mean dose of $10 \mathrm{cGy}$, in which a particle would traverse the nucleus in about $50-60 \%$ of the cells, p21 Waf1 was induced in the majority of cells whether lindane was present or absent. Its induction in a greater proportion of cells in the exposed control culture could be because of a bystander effect that is inhibited in the presence of lindane.

The dye-transfer data in Fig. 3 provide evidence that AG1522 cells are GJIC-competent. Intact cells are impermeable to Lucifer yellow; however, the dye permeates into cells that are damaged, and owing to its low molecular mass (457.2 Da), the dye subsequently migrates readily into neighboring cells through gap junctions. Fig. $3 A$ shows extensive transfer of Lucifer yellow in control cultures where a row of cells was scraped with a scalpel blade. The elongated morphology of AG1522 fibroblasts that express connexin43, and the use of confluent density-inhibited cultures, maximize interaction among cells and result in optimum dye transfer. The lack of dye transfer beyond the damaged cells at the edge of the scrape (when the cultures were incubated in the presence of $40 \mu M$ lindane) confirms the ability of lindane to inhibit GJIC in human fibroblasts (Fig. $3 B$ ).

Differential Activation of p21Waf1 Expression in Low Fluence $\alpha$ Particle-Exposed Isogenic Cell Strains That Differ in Their Ability to Perform Gap Junction Intercellular Communication. Inhibitors such as lindane may not, however, be specific in their action. To examine the involvement of intercellular communication in bystander effects after low fluence exposure in a direct manner, confluent cultures of two related rat epithelial cell lines that differ in their ability to perform gap junction communication were exposed to $\alpha$-particle radiation. The dye transfer experiments in Fig. $4 A$ indicate that WB-F344 cells are GJIC competent; Lucifer yellow readily migrates to adjacent cells. However, their ability to perform GJIC is sensitive to inhibition by lindane (Fig. 4B). The WM-aB1 cells were derived from WB-F344 cells and are deficient in GJIC, as indicated by their inability to
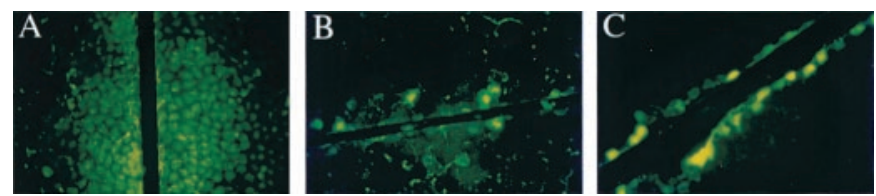

Fig. 4. (A) Transfer of Lucifer yellow through gap junction in WB-F344 confluent density inhibited cultures, and (B) inhibition of its transfer by $40 \mu \mathrm{M}$ lindane. (C) Inability to transfer Lucifer yellow to adjacent cells in gap junctiondeficient WM-aB1 cells.
GJIC competent

$\begin{array}{lllllllll}0 & .3 & 6 & 2 & 3 & 5 & 10 & 20 & 85\end{array}$

p21 Waf1

$\alpha$-tubulin
GJIC deficient

$\begin{array}{llllllllll}0 & .3 & 6 & 2 & 3 & 5 & 10 & 20 & 85 & \mathrm{cG} y\end{array}$

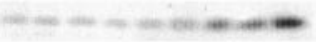

Fig. 5. Expression of $\mathrm{p} 21^{\text {Waf1 } 1}$ in protein lysates from gap junction-competent WB-F344 or gap junction-deficient WM-aB1 confluent cultures after exposure to $\alpha$-particles. Cells were harvested $4 \mathrm{~h}$ after the exposure and proteins were examined by Western blot analyses.

transfer Lucifer yellow to adjacent cells after scraping of the monolayer (Fig. 4C). The Western blot analyses data in Fig. 5 show an increase in $\mathrm{p} 21^{\text {Waf1 }}$ levels in confluent WB-F344 cultures exposed to mean doses as low as 0.3 cGy. In WM-aB1 cultures, an increase in p $21^{\text {Waf1 }}$ levels is significant only at mean doses of $5 \mathrm{cGy}$ or higher. Therefore, the magnitude of the response in the GJIC-competent cells and the lack of $\mathrm{p} 21^{\text {Waf1 }}$ up-regulation in WM-aB1 cultures that have been exposed to low mean doses strongly support the involvement of GJIC in the bystander gene-expression response. This is further confirmed by the in situ immunofluorescence data in Fig. 6 Upper that shows the induction of $\mathrm{p} 21^{\text {Waf1 }}$ in confluent cultures exposed to a mean dose of 0.3 cGy. Whereas small clusters of responding cells were observed in WB-F344 cells, only single isolated WM-aB1 cells invariably exhibited up-regulation of $\mathrm{p} 21^{\text {Waf1 }}$ after exposure to 1.0 cGy (Fig. 6 Lower). These rat cells are much smaller than the AG1522 human fibroblasts, and at these mean doses to the monolayer, $1 \%$ or less of the cells would have their nuclei traversed by an $\alpha$-particle.

The WM-aB1 cells were transformed by the mutagenesis of the WB-F344 parental-cell line (15). To exclude effects because of mutagenesis other than loss of GJIC, we tested the induction of the $\mathrm{p} 53 / \mathrm{p} 21^{\text {Waf1 }}$-signaling pathway after low fluence $\alpha$-particle irradiation of low passage MEFs from wild-type and
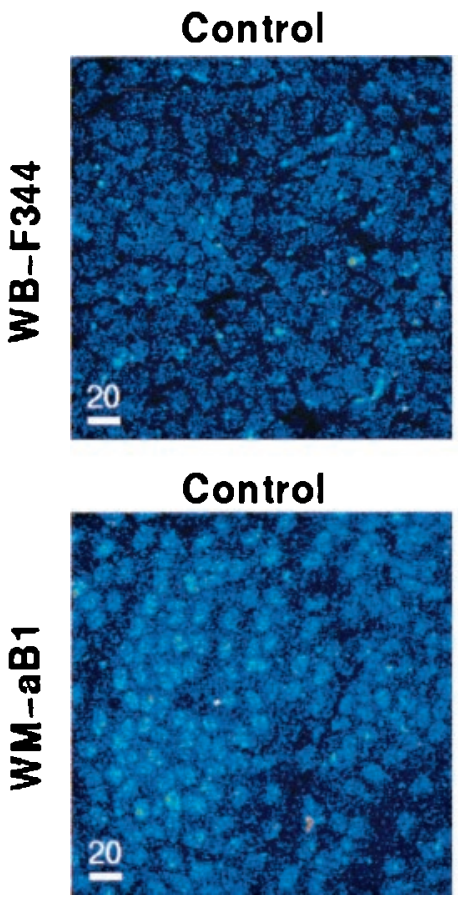

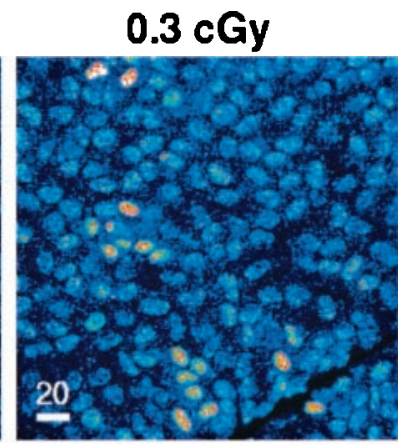

$1.0 \mathrm{cGy}$

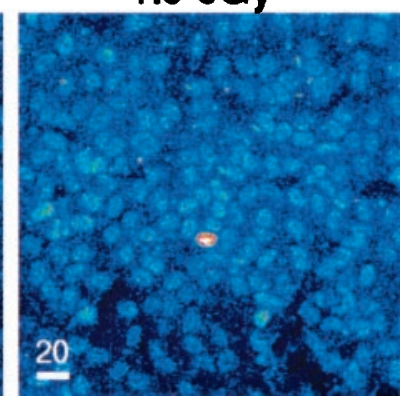

Fig. 6. (Upper) In situ immunofluorescence detection of p21 Waf1 expression in control nonirradiated WB-F344 cultures and cultures exposed to 0.3 cGy of $\alpha$-particles. (Lower) Expression of p21Waf1 in control nonirradiated and $1 \mathrm{cGy}$ exposed cultures of GJIC-deficient WM-aB1 cells. 


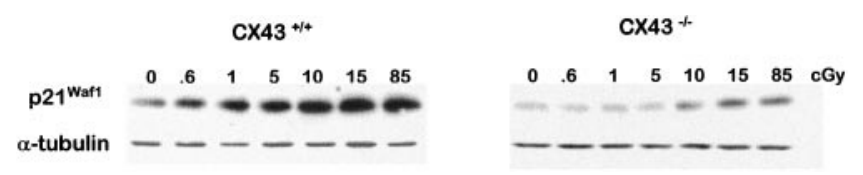

Fig. 7. Western analyses of p21Waf1 expression in lysates from isogenic wild-type or connexin $43^{-1-}$ cultures exposed to $\alpha$-particles. Cells were harvested $4 \mathrm{~h}$ after the exposure.

isogenic connexin43 knockout. The data in Fig. 7 are similar to those for WB-F344 and WM-aB1 cells (Fig. 5); they indicate a lack of detectable increase in $\mathrm{p} 21^{\text {Waf } 1}$ expression in connexin $43^{-1-}$ cells exposed to mean doses less than $10 \mathrm{cGy}$. In contrast, $\mathrm{p} 21^{\text {Waf1 }}$ was induced in wild-type cells after exposure to mean doses as low as 0.6 cGy. Collectively, these data strongly support the involvement of GJIC in the bystander geneexpression response observed in confluent density-inhibited cell cultures exposed to low fluences of $\alpha$-particles.

DNA Damage Is Induced at Levels Higher Than Expected in LowFluence-Exposed Human-Diploid Fibroblast Cultures: Inhibition by Lindane. To investigate whether the bystander induction of the stress-inducible p $21^{\text {Waf } 1}$ protein (Figs. 1 and 2) is associated with higher-than-expected levels of DNA damage after cellular exposure to low fluences of $\alpha$-particles, we measured the frequency of micronucleus formation in confluent cultures of AG1522 fibroblasts held in confluence for $3 \mathrm{~h}$ after the exposure. Compared with the control (nonexposed cells), the data in Fig. 8 indicate a 3 -fold increase in the induction of micronuclei after exposure to mean doses in the range of 1-3 cGy, and only a 4-fold increase after exposure to $10 \mathrm{cGy}$. At a mean dose of $10 \mathrm{cGy}$, 10 -fold more cells in the population experience a nuclear traversal by an $\alpha$-particle than those at a mean dose of 1 cGy. Therefore, the magnitude of the response at low fluences suggests that nontraversed bystander cells were also subject to DNA damage. To investigate the involvement of GJIC, lindane was added to the cultures $2 \mathrm{~h}$ before exposure and remained for $3 \mathrm{~h}$ thereafter. A highly significant reduction in the frequency of micronucleus formation was observed in cultures exposed to 1 or 2 cGy. At $10 \mathrm{cGy}$, lindane did not reduce the frequency of micronucleus formation in confluent cultures exposed to this same mean dose (Fig. 8). These data thus suggest that DNA damage may be the signal for the bystander induction of $\mathrm{p} 21^{\text {Waf1 }}$ in low fluence-exposed confluent-cell cultures. However, both effects may also be independent consequences of signals communicated from irradiated to bystander cells.

To further ascertain the involvement of DNA damage in the bystander induction of $\mathrm{p} 21^{\text {Waf1 }}$, we measured the levels of phosphorylation of Ser-15 in p53. Phosphorylation of p53 in Ser-15 has been shown to be dependent on the ataxia telangiectasia mutated gene in cells exposed to DNA damaging agents. However, its role in the activation of p53 is not clear (previously reviewed in ref. 16). The data in Fig. 9 indicate an increase in p53 phosphorylation after exposure of AG1522 cells to mean doses

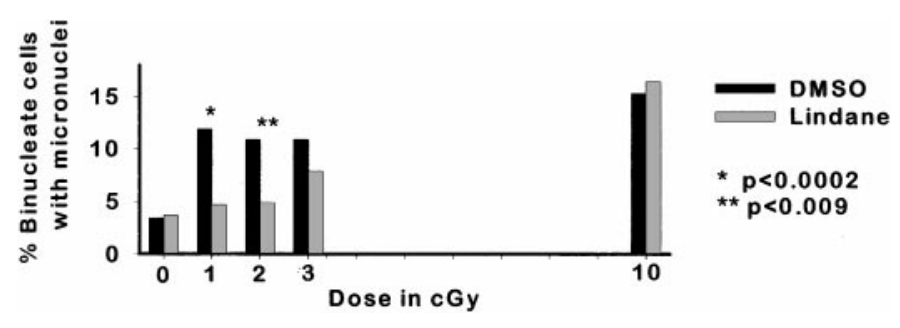

Fig. 8. Micronucleus formation in $\alpha$-particle-exposed AG1522 cultures in the presence or absence of lindane. $P$ values were determined by the $\chi^{2}$ test.

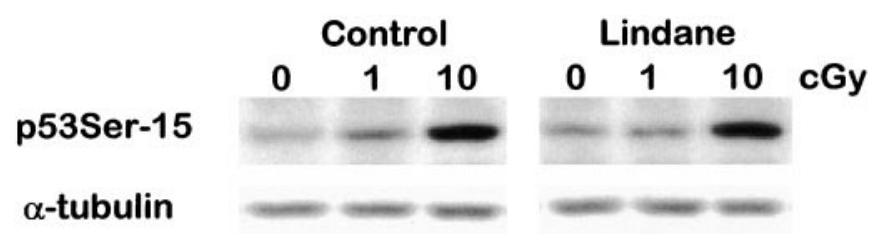

Fig. 9. Detection of Ser-15 phosphorylation in p53 after exposure of confluent AG1522 cultures to $\alpha$-particles in the presence or absence of the gap junction-inhibitor lindane.

as low as $1 \mathrm{cGy}$. This increase at $1 \mathrm{cGy}$ was attenuated in the presence of $40 \mu \mathrm{M}$ lindane. Therefore, these data further support the occurrence of DNA damage in bystander cells and implicate GJIC in its induction.

\section{Discussion}

Although much evidence for the existence of bystander responses to ionizing radiation has accumulated recently $(1-8,17$, $18)$, the mechanisms underlying the observed effects remain obscure. The gene expression data obtained in this study with confluent cultures of human and rodent cells exposed to very low fluences of $\alpha$-particles indicate that the effects of these particles are not confined to cells whose DNA is directly damaged by a traversing particle, and they provide direct evidence for the involvement of GJIC in mediating the bystander response. The observation that the induction of $\mathrm{p} 21^{\text {waf } 1}$ expression detected in situ occurs in aggregates of neighboring gap junction-competent cells far exceeding the expected number that would receive direct DNA damage (Figs. $1 B$ and $6 A$ ) indicates clearly that nontraversed bystander cells participate in the overall response of the exposed cultures, and suggests that this response could be mediated by GJIC. The involvement of GJIC was confirmed by the lack of detectable $\mathrm{p} 21^{\text {waf1 }}$ induction by Western analyses in protein lysates from cells that are genetically or chemically gap-junction-compromised (Figs. $2 A, 5 B$, and 7), and, importantly, by studies with in situ immunostaining. In situ immunofluorescence analysis of $\mathrm{p} 21^{\text {Waf1 }}$ expression in cells lacking GJIC (after exposure to a low mean dose of $0.3 \mathrm{cGy}$, by which $2 \%$ or less of nuclei are traversed by an $\alpha$-particle) revealed that it was induced only in single cells that were well secluded from each other (Figs. $2 B$ and $6 B$ ), as opposed to its induction in aggregates of cells (as did occur in competent cell cultures; Figs. $1 B$ and $6 A$ ). These data thus suggest that cultures of cells exposed to low fluences of $\alpha$-particles respond as a whole to the radiation stress with similar signaling pathways induced in nontraversed and traversed cells, and directly implicate GJIC as a mechanism mediating these effects. These results imply that the modeling of dose-response relationships based on the number of cells hit, as has been commonly used in risk analysis, may not be a valid approach.

Gap junctions are dynamic structures that have been shown to be critical for diverse functions such as early developmental events, oncogenic transformation, cell growth, propagation of excitation in muscle cells, and central nervous system neurons (19). Their role in radiation-induced biological effects was postulated earlier (20), and recent studies with chemical inhibitors of GJIC $(4,7,8,21)$ or connexin43-transfected cells (22) have explored their involvement in the induction and propagation of various radiation-induced effects such as modulation of gene expression, cell survival, and mutation induction. Through in situ techniques and the use of knockout cells, this report provides direct evidence for the participation of connexin43 gap junctions in the response to radiation stress and their role in mediating radiation-induced bystander effects. 
Whereas the inhibition of the bystander response in cells that are genetically compromised to perform connexin43-mediated GJIC confirms the involvement of this specific mechanism in the observed effects, our data do not preclude that the effects of gap junction inhibitors may vary in different cell types. For example, it was recently shown (23) that lindane differentially modulates calcium levels in peripheral blood lymphocytes and phagocytes. Also, our findings do not exclude mechanisms other than GJIC from having a role in the bystander response in confluent cultures exposed to low fluences of $\alpha$-particles (24). With the endpoints of gene expression and micronucleus formation, our work in progress is consistent with that of Narayanan et al. (25) and indicates that reactive oxygen species, as well as membraneoriginating pathways, participate in the bystander response. We are investigating whether these various mechanisms share common upstream signaling events, and whether there is crossover among them. The results of such studies may be informative as to the signaling events leading to activation of the connexin proteins. Importantly, the nature of the communicated molecule or molecules and the in situ identification of cells that have been traversed remain to be investigated.

The up-regulation of $\mathrm{p} 21^{\text {Waf1 }}$ in bystander cells was associated with a greater frequency of micronucleus induction than expected at mean doses of 1-2 cGy (Fig. 8). Such an increased frequency is consistent with the findings of Prise et al. (5). Its reduction in the presence of lindane (Fig. 8) suggests that DNA damage also occurs in bystander cells, and that GJIC may be involved in signaling the process. The induction of micronuclei and the cyclin-dependent kinase inhibitor $\mathrm{p} 21^{\text {Waf } 1}$ in bystander cells is also consistent with the recently reported $\mathrm{G}_{1}$ arrest occurring in a greater-than-expected number of cells in human fibroblasts exposed to a mean dose of 1 cGy of $\alpha$-particles (26). We studied micronucleus formation as a surrogate measure of DNA damage. Micronuclei arise predominantly from nonrejoined DNA double-strand breaks (27), which have been strongly implicated in the process of cancer development in humans (28). If DNA damage were to occur in bystander cells in vivo, and these cells survived such damage, these results would impact significantly on the assessment of cancer risk initiated by low fluence exposures to $\alpha$-radiation. On the other hand, dead cells stimulate compensatory hyperplasia in a tissue in vivo, which is a potentially tumor-promoting condition.

1. Nagasawa, H. \& Little, J. B. (1992) Cancer Res. 52, 6394-6396.

2. Deshpande, A., Goodwin, E. H., Bailey, S. M., Marrone, B. L. \& Lehnert, B. E. (1996) Radiat. Res. 145, 260-267.

3. Nagasawa, H. \& Little, J. B. (1999) Radiat. Res. 152, 552-557.

4. Zhou, H., Randers-Pehrson, G., Waldren, C. A., Vannais, D., Hall, E. J. \& Hei, T. K. (2000) Proc. Natl. Acad. Sci. USA 97, 2099-2104.

5. Prise, K. M., Belyakov, O. V., Folkard, M. \& Michael, B. D. (1998) Int. J. Radiat. Biol. Relat. Stud. Phys. Chem. Med. 74, 793-798.

6. Hickman, A. W., Jaramillo, R. J., Lechner, J. F. \& Johnson, N. F. (1994) Cancer Res. 54, 5797-5800.

7. Azzam, E. I., de Toledo, S. M., Gooding, T. \& Little, J. B. (1998) Radiat. Res. 150, 497-504

8. Bishayee, A., Rao, D. V. \& Howell, R. W. (1999) Radiat. Res. 152, 88-97.

9. Metting, N. F., Koehler, A. M., Nagasawa, H., Nelson, J. M. \& Little, J. B (1995) Health Phys. 68, 710-715.

10. El-Fouly, M. H., Trosko, J. E. \& Chang, C.-C. (1987) Exp. Cell Res. 168, 422-430.

11. Reznikoff, C. A., Bertram, J. S., Brankow, D. W. \& Heidelberger, C. (1973) Cancer Res. 33, 3239-3249.

12. Oh, S. Y., Dupont, E., Madhukar, B. V., Briand, J.-P., Chang, C.-C., Beyer, E. \& Trosko, J. E. (1993) Eur. J. Cell Biol. 60, 250-255.

13. Eckner, R., Ewen, M. E., Newsome, D., Gerdes, M., Decaprio, J. A., Lawrence, J. B. \& Livingston, D. M. (1994) Genes Dev. 8, 869-884.

14. Fenech, M. \& Morley, A. A. (1986) Mutat. Res. 161, 193-196.

15. Tsuchimoto, G., Chang, C. C., Trosko, J. E. \& Matsumura, F. (1983) Arch. Environ. Contam. Toxicol. 12, 721-730.
The DNA-damage-dependent phosphorylation of Ser-15 in p53 (Fig. 9) suggests that DNA damage in bystander cells precedes activation of the signaling pathways leading to this specific event. It is not yet known whether the transmitted signal or signals from irradiated cells to bystander cells cause in these cells DNA damage that leads to the alterations observed in gene expression (Figs. 1 and 2). Alternatively, the transmitted signal or signals may directly activate signal-transduction pathways leading to DNA damage and cell death in the bystander cells.

This study and others $(1-8,17)$ indicate that the level of damage in bystander cells measured several hours after the exposure of confluent cultures to $\alpha$-particles exceeds that arising from normal metabolism. These findings are different from data obtained with sparsely ionizing (low Linear Energy Transfer) radiation (29), whereby a $\gamma$-ray dose as little as $0.1 \mathrm{cGy}$ has been reported to induce a protective mechanism against damage from endogenous metabolism or from a subsequent radiation exposure. Whereas progress has occurred in radiobiological research tools, much remains to be learned about mechanisms underlying low and high Linear Energy Transfer radiations. An understanding of the mechanisms underlying various biological effects induced in vitro in cell populations exposed to low fluences of $\alpha$-particles are directly relevant to the assessment of health risks to the public from exposure to radon. It is currently estimated that $10-14 \%$ of lung cancer deaths in the U.S.A. are linked to $\alpha$-particles from radon gas in the environment (30). Moreover, these studies are pertinent to the hot-particle problem, and the biological effects of incorporated radionuclides used clinically in the diagnosis and treatment of various medical conditions. These studies are also pertinent to our understanding of the observations made during experimental gene therapy, whereby cells transduced with a drug-converting enzyme are cytotoxic to bystander cells (31), or where bystander cells protect transduced cells exposed to the pro-drug (32).

We are grateful to Dr. James Trosko for providing the WB-F344 and WM-aB1 cells and to Caterina Sellito for the connexin43-heterozygous mice. We thank Tamara Gooding for dedicated technical support; Drs. Hatsumi Nagasawa, William Dahlberg, Helene Hill, Roger Howell, and Anupam Bishayee for helpful discussions; and Jean Lai for performing confocal microscopy. This work was supported by Research Grant FG02-98ER62685 from the United States Department of Energy and Center Grant ES-00002 from the National Institutes of Health.

16. Ashcroft, M. \& Vousden, K. H. (1999) Oncogene 18, 7637-7643.

17. Mothersill, C. \& Seymour, C. B. (1998) Radiat. Res. 149, 256-262.

18. Vance, M. M. \& Wiley, L. M. (1999) Radiat. Res. 152, 544-551.

19. Simon, A. M. \& Goodenough, D. A. (1998) Trends Cell Biol. 8, 477-483.

20. Trosko, J. E., Chang, C. C. \& Madhukar, B. V. (1990) Radiat. Res. 123, 241-251.

21. Ishii, K. \& Watanabe, M. (1996) Int. J. Radiat. Biol. Relat. Stud. Phys. Chem. Med. 69, 291-299.

22. Luo, C., Macphail, S. H., Dougherty, G. J., Naus, C. C. \& Olive P. L. (1997) Exp. Cell Res. 234, 225-232.

23. Betoulle, S., Duchiron, C. \& Deschaux, P. (2000) Toxicology 145, 203-215.

24. Lehnert, B. E. \& Goodwin, E. H. (1997) Cancer Res. 57, 2164-2171.

25. Narayanan, P. K., Goodwin, E. H. \& Lehnert, B. E. (1997) Cancer Res. 57, 3963-3971.

26. Azzam, E. I., de Toledo, S. M., Waker, A. J. \& Little, J. B. (2000) Cancer Res. 60, 2623-2631.

27. Fimognari, C., Sauer-Nehls, S., Braselmann, H. \& Nusse, M. (1997) Mutagenesis 12, 91-95.

28. Karran, P. (2000) Curr. Opin. Genet. Dev. 10, 144-150.

29. Azzam, E. I., de Toledo, S. M., Raaphorst, G. P. \& Mitchel, R. E. (1996) Radiat. Res. 146, 369-373.

30. National Research Council, Committee on the Biological Effects of Ionizing Radiations, (1998) Health Effects of Exposure to Radon (BEIR VI) (Natl. Acad. Press, Washington, DC).

31. Aghi, M., Hochberg, F. \& Breakefield, X. O. (2000) J. Gene Med. 2, 148-164.

32. Wygoda, M. R., Wilson, M. R., Davis, M. A., Trosko, J. E., Rehemtulla, A. \& Lawrence, T. S. (1997) Cancer Res. 57, 1699-1703. 